\title{
Visita del profesor Dr. Mathijs Lamberigts en el octogésimo aniversario de la Facultad de Teología
}

\author{
Sandra Arenas
}

La Facultad de Teología comenzó su vida académica en marzo de 1935. Por esa razón, desde fines de 2014 su Dirección proyectó para el 2015 un año de celebraciones de su octogésimo aniversario. En este contexto y dentro de otras iniciativas, se organizó para el segundo semestre una semana de actividades académicas que quisieron estar circunscritas a la conmemoración de la clausura del Concilio Vaticano II, hace ya 50 años.

Para ello se invitó al profesor Mathijs Lamberigts, Decano de la Facultad de Teología de la Universidad Católica de Lovaina (Katholieke Universiteit Leuven) y Director del Centro Interdisciplinario de Estudios del Concilio Vaticano II. El profesor Lamberigts estudió filología clásica, patrología e Historia de la Iglesia tanto en Holanda como en Bélgica y ha desarrollado su carrera académica focalizada fundamentalmente en dos ejes de investigación: en la historia y teo- logía de San Agustín de Hipona y en la historia y teología del Concilio Vaticano II. Como historiador del Concilio, ha estado vinculado a los proyectos de investigación internacional más relevantes de las últimas décadas y por ello, para la Facultad, su visita significaba una buena ocasión para celebrar su aniversario institucional junto a otro aniversario de carácter más global/eclesial, convocando a diversos eventos académicos entre la semana del 13 al 16 de octubre de este año.

Con diversidad de orientaciones temáticas, se intentó reunir a diversas audiencias, lo que posibilitó el intercambio académico en variados niveles. El martes 13 en la mañana se abrió la semana de celebraciones con un Coloquio Interdiciplinario sobre el "Pluralismo Religioso y el Espacio Público" organizado por el Centro de Estudios de la Religión junto a la Facultad de Teología. Además de una mesa con repre- 
sentación de tres áreas del saber: derecho (profesora Ana María Celis), filosofía política (profesor Olof Page) y comunicaciones (profesor Eduardo Arriagada); M. Lamberigts atendió en su exposición a las implicancias sociales de la teología de las religiones en el Concilio con un texto titulado "Vatican II, Interreligious Dialogue, Religious Freedom, Service to the World". Con notable agudeza, penetró en el corazón del Evento Conciliar, el cual pasó desde el monólogo al diálogo, posibilitando una nueva era de relaciones entre la Iglesia y el espacio público. Ese mismo día, el profesor participó de la tradicional sesión mensual del Seminario Interno de Profesores de la Facultad de Teología.

Dada su expertise en la materia, su visita fue vista como una extraordinaria ocasión para convocar a 13 investigadores de tres países -Argentina, Perú y Chile- con trabajos en curso sobre el Concilio. El miércoles 14 se realizó entonces un "Seminario de Investigadores sobre el Concilio Vaticano II", un espacio pensado para la socialización de seis trabajos histórico-teológicos y de recepción latinoamericana, algunos ya terminados y otros en proceso. Estas presentaciones fueron precedidas por una exposición del profesor M. Lamberigts sobre el "Estado actual de las investigacio- nes del Concilio”. Esa presentación permitió una fecunda y activa discusión plenaria, antes y después de las exposiciones locales, de la cual se beneficiaron también los cinco estudiantes de magíster en temas afines que estaban presentes.

Para el jueves 17 se organizaron dos eventos académicos, un Seminario Patrístico y una Conferencia abierta. El primero, fue organizado por el Prof. Rodrigo Polanco y convocó a algunos profesores de filosofía y teología que trabajan tanto en el área patrística como también en temas de moral y familia. Este Seminario buscaba reflexionar en torno a un tema agustiniano que tiene gran relevancia en el debate teológico-moral actual: la influencia de Agustín en el concepto de matrimonio en la Iglesia Católica. Por ello se pidió a M. Lamberigts que, como experto en San Agustín, expusiera acerca del pensamiento agustiniano sobre el matrimonio, presentación que dejó en evidencia que en la obra agustiniana el matrimonio fue siempre visto como un bonum en su propio lugar y que el criterio ético para la evaluación moral de los seres humanos sigue siendo la rectitud ante Dios y no el estado de vida de los sujetos. El debate plenario se gestó espontáneamente entre los asistentes, tanto durante como después de la presentación. 
La Conferencia abierta se realizó en la Casa Central de la Universidad y convocó a alrededor de 90 personas de ambientes académicos y eclesiales diversos. El objetivo fue realizar un balance y sondear perspectivas en el cincuentenario del Concilio Vaticano II. En esta ocasión, el profesor lovaniense compartió la mesa con el profesor Joaquín Silva, quien respondió contextualmente a su texto. Titulada "Vatican II: Some Retrospective Observations", la presentación de M. Lamberigts revisó los principales ejes temáticos que, desde una mirada histórico-teológica, sitúan al Concilio como un evento de recepción de movimientos de renovación gestados en las décadas anteriores, y como un evento que, en estas cinco décadas, ha sido recibido no homogéneamente. La historicidad, contextualidad, pastoralidad y ecumenicidad vendrían a resignificar al catolicismo romano de los 60 y constituirían para M. Lamberigts- aún desafíos actuales a nivel teológico, doctrinal y pastoral.

Finalmente, junto al representante de los estudiantes de post- grado Mauricio Sepúlveda, se organizó un Seminario-Almuerzo con investigadores de postgrado, al cual asistieron profesores e investigadores tanto de magíster como de doctorado en teología. El objetivo fue conversar cuestiones relativas a la diversidad de métodos en el quehacer teológico desde preguntas concretas surgidas de las propias investigaciones. En él, M. Lamberigts introdujo la discusión con una exposición en la que desde su propia biografía académica situó el 'problema' del método investigativo en el sujeto que investiga, con su propia formación, sus particulares intereses, su línea de investigación, sus relaciones, hallazgos, preguntas, cruces... Esta exposición dio pie a una amplia y muy fecunda discusión desde la experiencia investigativa singular de los asistentes.

La visita del decano lovaniense contribuyó a darle un marco académico de interés global a la semana de aniversario de la Facultad de Teología. De esa manera, hacer memoria local y universal para proyectarse institucionalmente, se convirtió en un buen escenario para las celebraciones. 
